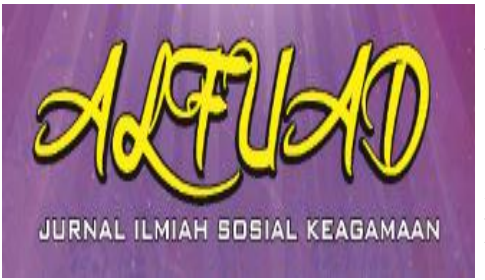

ALFUAD JOURNAL, 4 (1), 2020, (25-34)

(E-ISSN 2714-7606 P-ISSN 2614-4786 )

Available online at

http://ecampus.iainbatusangkar.ac.id/ojs/index.php/alfuad

\title{
POLITIK SEBAGAI JALAN KEBAHAGIAAN: REFLEKSI FILSAFAT SOSIAL DAN POLITIK ISLAM AL-FĀRĀB⿳亠丷厂
}

\section{Endrika Widdia Putri}

UIN Sunan Kalijaga Yogyakarta,

Indonesia

E-mail: endrikawiddiaputri@yahoo.co.id

\begin{abstract}
This article departs from the problem that the happiness of a country and its citizens lies in its politics. Whatever politics adopted by a country are all good. However, it is the human skills that govern politics that affect the course of politics. If those who manage are capable, then good politics will improve with the human skills that govern it - and vice versa. Departing from these problems, this article will look at how good politics in the eyes of philosophers. In particular, alFārāāi political thought - 9th century Muslim philosopher who lived during the Abbasid Dynasty. Al-Fārābī with its main state (al-Madinah al-Fädhilah) argues that the ideal state is a sovereign state to create a prosperous society based on the principles of equal rights, freedoms, and human unity. AlFārābi with political thought succeeded in expressing universal values of politics, and was able to map out the state classifications that existed in his day and did not rule out the possibility of existing today and formulated 12 (twelve) criteria for an ideal leader. In addition, al-Fārāā is considered a Muslim philosopher who began to talk about democracy. Although, al-Fārābi himself does not mention the term democracy except al-madinah al-jama'iyyah which is defined as a democratic state. Although al-Fārābī is not practical politics, his political thought is the result of his deep knowledge and experience. This is enough to prove that his political thinking is worth knowing and scrutinizing.
\end{abstract}

Keywords: Alfarabi, Politic, Ideal Nation, Happiness

\section{PENDAHULUAN}

Mengkaji isu sosial dan politik tidak semudah memecahkan persoalan matematika. Hal ini dikarenakan isu sosial dan politik berhubungan dengan manusiamakhluk unik sekaligus rumit. Tiap-tiap manusia memiliki pribadi dan masalah yang berbeda-beda yang tidak bisa dipukul rata atau digeneralisir secara keseluruhan.
Manusia dengan anugerah terindah yang dimilikinya, yaitu akal menjadikan ia berbeda dengan makhluk lainnya. Ia mampu membedakan mana yang baik dan mana yang tidak. Walau demikian, manusia tetap tak pernah lepas dari yang namanya masalah. Masalah tampaknya selalu menghantuinya- entah itu masalah sosial maupun politik. 
Tidak jelasnya sistem perpolitikan dapat dikatakan sebagai salah satu penyebab permasalahan-permasalahan sosial maupun politik itu sendiri tak pernah selesai untuk diperbincangkan. Manusia dengan segala perkembangan pemikirannya selalu berusaha memberi peluang untuk mengunakan sistem perpolitikan yang ada. Secara historis, dalam dunia Islam sendiri secara substansi pernah menggunakan sistem kekhalifahan, monarki, autoktasi, dan demokrasi Sejatinya, berbagai macamnya sistem perpolitikan atau pemerintahan, tujuan yang hendak dicapai bukankah agar semua warga negara yang ada merasakan kebahagiaan. Namun, mengapa sistem perpoltikan yang dianut oleh suatu negara tak selama-lamanya mampu memberikan cita-cita yang dikehendaki tersebut.

Hal demikian, merupakan suatu problem yang hendaknya bisa dipecahkan. Apakah tidak memungkinkan selamalamanya suatu negara menggunakan satu sistem perpolitikan dari awal negara itu hadir hingga ia tutup usia. Apa sebenarnya yang menjadi masalah di sini. Apakah sistem perpolitikannya atau manusia yang menjalankannya. Bagaimana hebatnyapun suatu sistem perpolitikan jika yang menguasai perpolitikan tersebut bukanlah manusia yang cakap- dalam arti tidak memenuhi kriteria-kriteria kepemimpinan.
Maka, tidak ada sistem perpolitikan yang cocok dalam suatu negara. Walau diganti dengan sistem perpolitikan yang lebih baik dari sebelumnya, yang muncul hanyalah permasalahan-permasalahan yang tak kan pernah terelakkan. Apapun sistem perpolitikan yang digunakan dalam suatu negara jika dipimpin oleh orang cakap, maka kebahagiaan sebagai tujuan politik tersebut akan tampak di mana-mana. Demikian pula sebaliknya.

Salah satu filosof Muslim yang berpartisipasi memyumbangkan pemikirannya dalam bidang ketatanegaraan adalah al-Fārābī. al-Fārābī dapat dikatakan filosof Muslim pertama yang menulis hampir komprehensif mengenai perpolitikan. Ia adalah filosof Muslim pertama yang berupaya menghadapkan, mempertalikan, dan sejauh mungkin menyelaraskan filsafat politik (Yunani) klasik dengan Islam, serta berupaya membuatnya bisa dimengerti di dalam konteks agama-agama wahyu (Bagir, 2006: 206-207). Al-Fārābī dengan konsep al-Madīnah al-Fādilah walau terpengaruh oleh konsep politik Plato dan Aristoteles, namun konsep politiknya tersebut banyak mencontoh bentuk dan hakikat kepemimpinan Rasulullah SAW. sebagai seorang rasul dan khalifah yang agung di muka bumi ini. Sikap kepemimpinan Rasulullah menjadi titik tolak 
Endrika Widdia Putri: Politik sebagai Jalan Kebahagiaan: Refleksi Filsafat Sosial Dan Politik...

kecenderungan al-Fārābī dalam melahirkan pemikiran mengenai konsep kenegaraan (Mahmudah, 2017).

Mengkaji pemikiran politik alFārābī menjadi suatu hal yang penting kiranya- dalam menyelesaikan permasalahan masyarakat yang mencari suatu bentuk negara ideal. Makanya, dalam paper ini akan dijelaskan bagaimana konsep negara utama atau ideal dan tujuannya menurut al-Fārābī. Serta, bagaimana sistem demokrasi dalam filsafat politik al-Fārābī.

\section{METODE}

Adapun metode penelitian kajian pustaka atau studi kepustakaan yaitu berisi teori teori yang relevan dengan masalah masalah penelitian. Pada bagian ini dilakukan pengkajian mengenai konsep dan teori yang digunakan berdasarkan literatur yang tersedia, terutama dari artikel-artikel yang dipublikasikan dalam berbagai jurnal ilmiah. Kajian pustaka berfungsi untuk membangun konsep atau teori yang menjadi dasar studi dalam penelitian. Kajian pustaka atau studi pustaka merupakan kegiatan yang diwajibkan dalam penelitian, khususnya penelitian akademik yang tujuan utamanya adalah mengembangkan aspek teoritis maupun aspek manfaat praktis. Sehingga dengan menggunakan metode penelitian ini penulis dapat dengan mudah menyelesaikan masalah yang hendak diteliti.

\section{HASIL DAN PEMBAHASAN}

Politik sebagai Jalan Kebahagiaan

Al-Fārābī

menuangkan

pemikirannya tentang negara utama dengan asumsi bahwa pencapaian kebahagiaan manusia hanya dapat diaktualisasikan dalam masyarakat, berdasarkan pada gotong royong dan solidaritas, di mana seorang manusia tidak terisolasi ( Kurmangaliyeva, 2016: 90). Melihat kepada kenyataan masa lalu pada masa Al-Fārābī dan sekarang sepertinya memang tidak memungkinkan untuk bahagia, jika tetap bersikeras hidup tanpa bantuan dan keterkaitan dengan orang lain. Ini melawan hukum alam. Fitrahnya manusia membutuhkan orang lain sebagai makhluk sosial dan hal ini mengantarkan manusia akan kebutuhan pada perpolitikan atau kepemerintahan (Sakarya, 2010: 48). Sebagaimana Aristoteles, Al-Fārāb̄̄ meyakini bahwa individu yang berwatak zoon politicon (makhluk kemasyarakatan) takkan memperoleh kebahagiaan, tanpa dukungan masyarakat. Oleh karenanya, alFārābī menolak kehidupan soliter (mengucilkan diri) yang disarankan oleh sebagian sufi (Fakhry, 2002: 52). 
Konsep kebahagiaan filosofis secara umum identik dengan konsep kesempurnaan manusia. Antara keduanya sama-sama konsep aktualitas diri yang diidentifikasi dengan konsep etis kebaikan (Mattila, 2011: 65). Kesempurnaan manusia menurut al-Fārābī sesuai dengan watak alamiah manusia itu sendiri, tidak akan tercapai tanpa berhubungan dengan manusia-manusia yang lain. Lebih lanjut, pendapatnya mengenai kebahagiaan dalam negara menekankan keharusan negara berdiri di atas landasan akhlak mulia dan kesanggupan berbuat baik. Kebaikan dan musyawarah kata al-Fārābī seperti yang dikutip dalam buku The Political Aspects of Islamic Philosophy adalah dua elemen penting dari kebajikan praktis (Mahdi, 1992: 107). Melakukan kebaikan dan bermusyawarah dalam suatu negara akan mengantarkan negara tersebut pada kebahagiaan. Makanya, moralitas dan musyawarah dijunjung tinggi dalam suatu negara bagi al-Fārābī.

Menurut al-Fārābī dalam kitabnya Risālah Tanbīh ila as-Sabīli as-Sa'ādah, al-Fārābī mengatakan bahwa kebahagiaan adalah kebaikan yang diinginkan untuk kebaikan itu sendiri (Alfarabi, 1987: 15). Artinya seseorang melakukan kebaikan adalah dengan motif karena suka melakukan kebaikan itu. Alasan seseorang melakukan kebaikan bukan karena apa-apa atau karena ada apanya. Tapi karena memang tahu kebaikan itu baik dan luar biasa manfaatnya. Segala hal yang membuat manusia bahagia adalah baik, begitu pula sebaliknya. Selain itu, alFārābī mengatakan kebahagiaan adalah tujuan hidup atau tujuan akhir dari segala yang dilakukan. Seseorang menjadi jujur, ikhlas, tidak sombong, menolong orang lain, maupun rajin tujuannya karena ingin bahagia, tidak ada lagi yang ingin dituju selain karena ingin bahagia. Tuhanpun menciptakan manusia untuk bahagia. Allah menyediakan semuanya untuk manusia, Allah selalu mempermudah manusia, karena Tuhan ingin manusia bahagia, dan tak ingin manusia susah. Jadi, kalau manusia tidak bahagia saat Tuhan telah mempermudah dan telah memberi segalanya kepada manusia berarti secara tidak langsung manusia sedang menyinggung perasaan Tuhan (Faiz, 2019). Tuhan adalah tempat kembali, kampung halaman manusia yang sesungguhnya. Berada dekat atau mengadakan kontak dengan-Nya, merupakan tujuan terakhir dari setiap diri manusia. Apabila kebahagiaan tertinggi adalah kebahagiaan dalam bersatu dengan Tuhan, kebahagiaan spiritual- yang diperoleh melalui persatuan atau kontak dengan yang ilahi berarti merupakan kebahagiaan yang tertinggi, yang pernah 
Endrika Widdia Putri: Politik sebagai Jalan Kebahagiaan: Refleksi Filsafat Sosial Dan Politik...

Tuhan karuniakan kepada manusia (Kartanegara, 2005: 75).

Selain itu, dalam kitabnya Tạhshīl al-Sa'ādah al-Fārābī mengatakan bahwa bangsa dan warga kota untuk mencapai kebahagiaan, baik di dunia maupun di akhirat adalah ketika manusia memenuhi empat jenis sifat-sifat utama/ keutamaan. Keutamaan menurut al-Fārābī adalah keadaan jiwa yang menimbulkan tindakan yang mengarah pada kesempurnaan teoritis. Artinya, keutamaan dari sesuatu adalah sesuatu yang menghasilkan keunggulan dan kesempurnaan dalam keberadaan dan tindakannya. Jiwa yang sempurna bagi al-Fārābī adalah jiwa yang tidak membutuhlan materi untuk bertahan hidup. Maksudnya, kematerian tempat tinggal jiwa tak menjadikan jiwa terpengaruh akan kematerian atau keduniawian tersebut, jiwa tetap berjalan dalam arus kesempurnaannya mencapai derajat tertinggi.

Adapun keutamaan-keutamaan tersebut yaitu, pertama, keutamaan teoritis, yaitu prinsip-prinsip ilmu pengetahuan yang diperoleh orang sejak semula tanpa dirasai, tanpa diketahui cara dan asalnya diperoleh, dan juga diperoleh dengan renungan kontemplatif, penelitian dan juga dari mengajar dan belajar. Kedua, keutamaan intelektual atau pemikiran, yaitu keutamaan yang dengannya memungkinkan orang mengetahui apa yang paling bermanfaat dalam tujuan yang utama. Termasuk dalam hal ini, kemampuan untuk membuat aturan-aturan, karena itu disebut dengan keutamaan pemikiran budaya (fadha'il fikriyyah madaniyyah). Ketiga, keutamaan akhlaki, yaitu keutamaan yang bertujuan untuk mencari kebaikan. Keempat, keutamaan praktis yang dapat diperoleh dengan dua cara, pernyataan-pernyataan yang memuaskan dan yang merangsang (Daudy, 1986: 48).

Terkait dengan pembagiaan keutamaan di atas Miriam Galtson dalam buku The Political Aspects of Islamic Philosophy menyebut bahwa inti kebahagiaan perspektif al-Fārābī adalah keutamaan teoritis dan keutamaan praktishemat penulis karena Miriam Galston mengabungkan keutamaan intelektual ke dalam keutamaan teoritis dan keutamaan akhlaki ke dalam keutamaan praktis. Baginya kebahagiaan tertinggi sejauh manusia mempraktekan keutamaan teoritis yang dimilikinya sehingga manusia bisa mencapai tingkat kemanusiaan yang paling sempurna.

\section{Demokrasi dalam Filsafat Politik al- Fārābī}

Berdasarkan pada sub bab sebelumnya, dengan merujuk kepada negara utama al-Fārābī sistem yang 
dikehendakinya adalah autokrasi. Namun, dalam kitabnya al-Siyāsah al-Madaniyyah ia menjelaskan sulitnya mewujudkan negara utama dengan serangkaian syarat yang ia ajukan, sehingga al-Fārābī menjelaskan negara demokrasi yang merupakan bagian dari negara Jahiliyyah adalah negara yang paling memungkinkan sebagai sistem politik yang baik. Al-Fārāō̄ dalam kitabnya al-Siyāsah al-Madaniyyah yang penulis kutip dari buku karangan Yamani “Antara al-Fārābì dan Khomeini: Filsafat Politik Islam" mengatakan bahwa:

"Sangatlah mungkin bahwa lamakelamaan orang-orang utama akan bermunculan di kota itu (demokrasi), yakni filosof, ahli retorika, dan penyair yang mengeluti berbagai hal. Ada kemungkinan pula untuk mengumpulkan, sedikit demi sedikit dari kota itu (orang-orang) tertentu (yang membentuk) bagian-bagian dari kota utama itu. Inilah hal terbaik yang (mungkin) terjadi di kota seperti ini" (Yamani, 2002: 73-74).

Lebih lanjut al-Fārābī menjelaskan bahwa:

"Segenap upaya keras dan tujuan kota-kota Jahiliah ada dalam kota seperti ini dengan cara yang sangat sempurna. Di antara semua (kota-kota jahiliah) itu, inilah kota yang paling terpuji dan bahagia. Secara lahiriah, ia seperti pakaian yang bersulam, yang penuh dengan celupan dan bentukbentuk warna-warni. Semua orang menyukainya, dan suka tinggal di dalamnya, karena semua kehendak atau keinginan manusia akan dipenuhi oleh kota ini. Berbagai bangsa berimigrasi ke kota ini untuk mukim, dan kota ini pun lalu tumbuh berkembang secara luar biasa. Orang dari segala ras memadati kota ini, dan melalui perkawinan melahirkan anakanak yang kecenderungan mereka sangat beragam, dan dengan serta proses pendewasaan sangat beragam pula" (Yamani, 2002: 75).

Yamani penulis buku "Antara alFārābī. dan Khomeini: Filsafat Politik Islam" mengomentari pernyataan al-Fārābī di atas dalam konteks inilah al-Fārābī menyebutkan bahwa lama-kelamaan dapat bermunculan orang-orang bijak di kota seperti ini. Bagi al-Fārābī kota seperti ini memiliki kebaikan maupun keburukan yang lebih besar dibandingkan dengan kota-kota jahiliyyah lainnya. Semakin besar, semakin berperadaban, semakin padat penduduknya, semakin produktif, dan semakin sempurna kota ini, semakin besar pula kebaikan dan keburukan yang ada di kota ini (Yamani, 2002: 76). Meskipun al-Fārābī berpandangan bahwa negara demokrasi merupakan satu di antara enam negara jahiliyyah, al-Fārābī percaya bahwa membangun negara utama dan menegakkan pemerintahan orang bajik lebih efektif dan jauh lebih mudah dengan menggunakan negara demokrasi.

Penulis menilai bahwa pernyataan al-Fārābī di atas menunjukkan keoptimisan al-Fārābī pada sistem demokrasi yang akan memunculkan orang-orang hebat dalam negara demokrasi. Ini sebagai implikasi dari hakikat negara demokrasi yang 
Endrika Widdia Putri: Politik sebagai Jalan Kebahagiaan: Refleksi Filsafat Sosial Dan Politik...

dimaksud oleh al-Fārābī- negara yang tujuan inti para warganya adalah memperoleh kebebasan tanpa batas untuk melampiaskan hawa nafsu. Dalam kota ini tidak seorangpun berhak melarang apa yang menjadi keinginan, dan apa yang dilakukan oleh warga kota. Oleh karenanya, negara demokrasi menjadi bagian dari negara jahiliyyah yang merupakan lawan dari negara utamanya. Al-Fārābī mengkategorikan negara demokrasi dalam jahiliyyah karena kebebasan tanpa batas manusia dalam melampiaskan hawa nafsu. Penulis melihat kebimbangan al-Fārābī antara dua hal satu sisi negara demokrasi akan melahirkan orang-orang yang hebat karena kebebasan yang ada di sisi lain akan melahirkan kebebasan yang membabi buta. Makanya, al-Fārābī mengkategorikan negara demokrasi ke dalam negara jahiliyyah.

Penduduk kota ini beranggapan bahwa semua manusia itu (memiliki status) sama, tidak ada perbedaan antara satu dengan yang lain, tidak boleh berkuasa atas yang lain, dan berhak untuk melakukan segala sesuatu sekehendak hatinya. Situasi kota yang seperti ini memunculkan berbagai perilaku dan keinginan dalam masyarakatnya. Ada yang berperilaku hina, ada pula yang terpuji. Masing-masing dari mereka memiliki pimpinannya sendiri. Pimpinan mereka hanya memiliki kewenangan mengakomodasi kemauan dan keinginan warga sesuai kesepakatan. Dengan kata lain, pimpinan tidak bisa berbuat apa-apa, sebab tidak jelas (rancu) hubungan antara yang memimpin dan yang dipimpin. Jika pun ada pemimpin, itu hanya untuk menyelenggarakan kehendak warga (penduduk) kota saja, dan hanya berperan sebagai penyalur aspirasi. Hak-hak individu dalam kota demokratik ini tidak diakui, satu untuk semua dan semua untuk satu.

Dari penjelasan di atas dapat dipahami bahwa al-Fārābī mengedepankan nilai-nilai kebebasan, persamaan hak, dan kesatuan manusia. Jelasnya, kebebasan bagi al-Fārābī adalah mendapatkan kesempatan yang sama untuk menggunakan bakat yang dimiliki setiap warga. Prinsip ini menjunjung tinggi kebebasan individu yang berlaku untuk semua anggota masyarakat. Selanjutnya, kebebasan mensyaratkan individu atas kolektivitas sosial apapun. Oleh karena itu, pandangan-pandangan dalam ranah publik setidaknya harus terbuka bagi penilaian kritis dan perubahan sehingga validitasnya dapat diuji dan diperkuat. Sedang, persamaan hak yang dimaksud al-Fārābī yaitu meminimalisir dominasi kekuasaan serta meluruskan cita-cita kemanusiaan universal agar kehidupan bersama benar- 
Endrika Widdia Putri: Politik sebagai Jalan Kebahagiaan: Refleksi Filsafat Sosial Dan Politik...

benar menjadi arus utama dalam berdemokrasi. Al-Fārābī sangat mendorong terbentuknya negara egaliter, sebab dalam pendangannya ingin melahirkan harmonisme kehidupan. Adapun kesatuan manusia- dalam pandangan al-Fārāb̄̄ bukan berarti menyatukan beberapa negara menjadi satu sebagai konsep komunisme atau politik Islam tetapi lebih kepada gagasan untuk membangun aliansi atau kerjasama antar bangsa agar tercipta masyarakat egaliter yang lebih luas (Mutiullah, 2019: 116).

Penulis menilai bahwa keinginan al-Fārābī akan negara utamanya dihuni oleh orang-orang yang bermoral sekaligus intelektual, dalam hal ini hanya manusiamanusia sempurnalah yang ada di negara utama al-Fārābī. Ini tentu berawal dari penglihatan al-Fārābī yang tidak adanya kebahagiaan pada pemerintahan kala itu. Selain, dipimpin oleh pemerintah yang tirani, juga dihuni oleh warga yang paham moralitas dan kurang intelektual. Berpatok pada "tidak ada yang tidak mungkin di dunia ini" bukan tidak memungkinkan apa yang diteorikan al-Fārābī terealisasikan walau dengan kemungkinan sangat sulit sekali. Makanya, negara demokrasi yang merupakan bagian dari negara jahiliyyah adalah negara yang paling memungkinkan menjunjung tinggi nilai-nilai dasar manusia, dikarenakan negara tersebut memberikan kebebasan bagi setiap negaranya, yang selanjutnya melahirkan nilai-nilai persamaan hak dan kesatuan manusia. Penghargaan yang luar biasa tentunya untuk al-Fārābī karena jasanya dalam memetakan teori perpolitikan yang bisa dibilang komprehensif pada masa itu menjadikan gebrakan baru dalam sejarah pemikiran filsafat Islam. Al-Fārābī setidaknya mampu memberikan pemikiran baru mengenai demokrasi, walau ia tidak menyebut istilah demokrasi. Oleh karena itu, tidak berlebihan kiranya kalau pemikiran al-Fārābī ini dijadikan landasan oleh pakar politik setelahnya untuk mengatakan bahwa hal itu adalah benih munculnya demokrasi, sekalipun al-Fārābī sendiri tidak pernah menyebut kata demokrasi dalam karya-karyanya (Muthhar, 2016: 46).

\section{KESIMPULAN}

Berdasarkan penjelasan di atas dapat disimpulkan bahwa negara utama menurut al-Fārābī adalah negara berdaulat untuk mewujudkan masyarakat sejahtera yang berdasar pada prinsip-prinsip persamaan hak, kebebasan, dan kesatuan manusia. Bagi al-Fārābī Kebahagiaan suatu negara tergantung pada aktivitas politiknya. Semakin baik sistem politik suatu negara semakin bahagia negara dan segala yang di dalamnya. Kebahagiaan 
dalam negara dapat dicapai ketika bangsa dan warga kota merealisasikan keutamaan teoritis menjadi keutamaan praktis. Penghargaan yang luar biasa tentunya untuk al-Fārābī karena jasanya dalam memetakan teori perpolitikan yang bisa dibilang komprehensif pada masanya. Hal ini tentu menjadikan gebrakan baru dalam sejarah filsafat Islam.

\section{DAFTAR PUSTAKA}

Abidin, A. Z. (2012). Konsep Ketatanegaraan Islam menurut alFārābī dan Ayatullah Khumaeni. Al-Mazahib, 1(2). http://ejournal.uinsuka.ac.id/syariah lalmazahib/article/view/1355.

Al-Ahwani, A. F. (1984). Filsafat Islam. Jakarta: Proyek Pembinaan Prasarana dan Sarana Perguruan Tinggi Agama..

Al-Fārābī, A. N. (1995). Taḥshīl alSa'ādah. Libanon: Dar wa Maktabah al-Hilal.

(1993). Al-Siyāsat al-Madaniyyah.

Beirut: Dār al-Masyriq.

- (1987). Risālah Tanbīh ila asSabìli as-Sa'ādah. Amman: Universitas Yordania.

. (1995). Arā' Ahl al-Madīnah alFādhilah. Beirut: Maktabah alHilal.

Ali, Y. (1991). Perkembangan Pemikiran Falsafi dalam Islam. Jakarta: Bumi Aksara.

Bagir, H. (2006). Buku Saku Filsafat Islam. Bandung: Penerbit Mizan.

Bakry, H. (1973). Di Sekitar Filsafat Skolastik Islam. Jakarta: Tutamas.
Daudy, A. (1992). Kuliah Filsafat Islam. Jakarta: PT Bulan Bintang.

Drajat, A. (2006). Filsafat Islam: buat yang pengen tahu. Jakarta: Penerbit Erlangga.

Fakhry, M. (2002). Sejarah Filsafat Islam: Sebuah Peta Kronologis. Terj. Zaimul Am. Bandung: Mizan.

Hamedi, A. (2013). Farabi's view on Happiness. International Journal of Advanced Research, 1(7). www.journalijar.com.

Hanafi, Ahmad. 1990. Pengantar Filsafat Islam. Jakarta: Bulan Bintang.

Hasan, M. (2015). Sejarah Filsafat Islam (Geneologis dan Transmisi Filsafat Timur ke Barat). Bandung: CV Pustaka Setia.

Iqbal, M., \& Nasution, A. H. (2010). Pemikiran Politik Islam: dari Masa Klasik hingga Indonesia Kontemporer. Jakarta: Kencana.

Khalidi, M. A. (2003). Al-Fārābī on the Democratic City. British Journal for the History of Philosophy, 11(3).

https://www.researchgate.net/ publication/232891856.

Kumar, M. Y. (2017). Islamic Political Thought: A Study of the Diverse Interpretations of Medieval Muslim Political Thinkers. Saudi J. Humanities Soc. Sci. 2. http://scholarsmepub.com/sjhss211/.

Kurmangaliyeva, G., \& Azerbayev, A. (2016). “Al-Fārābī 's Virtuous City and Its Contemporary Significance (Social State in Al-Fārābī 's Philosophy)". Anthropologist. 26 $(1,2)$ https://www.researchgate.net/p ublication/ 316961296. 
Labib, M. (2005). Para Filosof: Sebelum dan Sesudah Mulla Sadra. Jakarta: Penerbit al-Huda.

Mahdi, M. S. (1992). The Political Aspects of Islamic Philosophy. Harvard: Harvard University Press.

Mahmuda. 2017. “Konsep Negara Ideal/ Utama (al-Maḍinah al-Fādilah) menurut al-Fārābī”, al-Lubb, 2(2). http://jurnal.uinsu.ac.id/ index.php/lubb/article/view/1085.

Mattila, J. (2011). Philosophy as a Path to Happiness Attainment of Happiness in Arabic Peripatetic and Ismaili Philosophy. Finland: Helsinki University Print.

Muhammad, A. A. M. (2010). Filsafat Politik antara Barat dan Islam. Terj. Rosihon Anwar. Bandung: CV. Pustaka Setia.

Mustafa, A. (1997). Filsafat Islam. Bandung: CV. Pustaka Setia.

Muthhar, M. A. (2016). "Kontekstualisasi Filsafat Politik al-Fārābī dalam Pemikiran Politik Modern". Maraji: Jurnal Studi Keislaman. 3(1). September. Dalam https://pingpdf.com/pdf-marajijurnal-ilmu-keislaman.html.

Mutiullah. (2015). Filsafat Islam: Trajektori, Pemikiran dan Interpretasi. Yogyakarta: FA Press.
Netton, I. R. (1989). Al-Fārāā à and His School: Arabic Thought and Culture. New York: State University of New York Press.

Sakarya, S. (2016). "Al-Fārābī : A SplitIdentity?”. Akademik Hassasiyetler. https://dergipark.org.tr/en/pub/akad emik-hassasiyetler.

Sjadzali, M. (1990). Islam dan Tata Negara: ajaran, sejarah dan Pemikiran. Jakarta: UI-Press.

Soleh, K. (2016). Filsafat Islam: Dari Klasik hingga Kontemporer. Yogyakarta: ar-Ruzz Media.

Sukardi, I. (2017). "Negara dan Kepemimpinan dalam Pemikiran al-Farabi”. Al-A'raf, 14(2). JuliDesember. Dalam https://ejournal.iainsurakarta. ac.id/index.php/alaraf/article/view/959.

Supriyadi, D. (2013). Pengantar Filsafat Islam (Konsep, Flisuf, dan Ajarannya). Bandung: CV Pustaka Setia.

Yamani. (2002). Antara al-Fārābì dan Khomeini: Filsafat Politik Islam. Bandung: Mizan.

Zar, S. (2012). Filsafat Islam: Filosof dan Filsafatnya. Jakarta: Rajawali Pers. 